\title{
A conceptual replication of emotional intelligence as a second-stratum factor of intelligence
}

DOI:

10.1037/emo0000569

Document Version

Accepted author manuscript

Link to publication record in Manchester Research Explorer

\section{Citation for published version (APA):}

Evans, T., Hughes, D., \& Steptoe-Warren, G. (2019). A conceptual replication of emotional intelligence as a second-stratum factor of intelligence. Emotion. https://doi.org/10.1037/emo0000569

\section{Published in:}

Emotion

\section{Citing this paper}

Please note that where the full-text provided on Manchester Research Explorer is the Author Accepted Manuscript or Proof version this may differ from the final Published version. If citing, it is advised that you check and use the publisher's definitive version.

\section{General rights}

Copyright and moral rights for the publications made accessible in the Research Explorer are retained by the authors and/or other copyright owners and it is a condition of accessing publications that users recognise and abide by the legal requirements associated with these rights.

\section{Takedown policy}

If you believe that this document breaches copyright please refer to the University of Manchester's Takedown Procedures [http://man.ac.uk/04Y6Bo] or contact uml.scholarlycommunications@manchester.ac.uk providing relevant details, so we can investigate your claim.

\section{OPEN ACCESS}




\section{A conceptual replication of emotional intelligence as a second-stratum factor of intelligence}

Evans, T., Hughes, D. \& Steptoe-Warren, G.

Author post-print (accepted) deposited by Coventry University's Repository

Original citation \& hyperlink:

Evans, T, Hughes, D \& Steptoe-Warren, G 2019, 'A conceptual replication of emotional intelligence as a second-stratum factor of intelligence' Emotion.

DOI $10.1037 /$ emo0000569

ISSN 1528-3542

ESSN 1931-1516

Publisher: American Psychological Association

CAmerican Psychological Association, 2019. This paper is not the copy of record and may not exactly replicate the authoritative document published in the APA journal. Please do not copy or cite without author's permission. The final article is available, upon publication, at: https://psycnet.apa.org/record/2019-06651001?doi=1

Copyright $\odot$ and Moral Rights are retained by the author(s) and/ or other copyright owners. A copy can be downloaded for personal non-commercial research or study, without prior permission or charge. This item cannot be reproduced or quoted extensively from without first obtaining permission in writing from the copyright holder(s). The content must not be changed in any way or sold commercially in any format or medium without the formal permission of the copyright holders.

This document is the author's post-print version, incorporating any revisions agreed during the peer-review process. Some differences between the published version and this version may remain and you are advised to consult the published version if you wish to cite from it. 
Running Head: EMOTIONAL INTELLIGENCE AS A SECOND STRATUM FACTOR

\title{
A Conceptual Replication of Emotional Intelligence as a Second-Stratum Factor of
} Intelligence

\author{
Thomas Rhys Evans ${ }^{1}$ \\ David J. Hughes ${ }^{2}$ \\ Gail Steptoe-Warren ${ }^{1}$
}

${ }^{1}$ School of Psychological, Social and Behavioural Sciences, Coventry University, UK

${ }^{2}$ Alliance Manchester Business School, University of Manchester, UK

Corresponding author: Thomas Rhys Evans, School of Psychological, Social and Behavioural Sciences, Coventry University, Coventry, UK, CV1 5FB.

Email: ab6443@coventry.ac.uk 


\begin{abstract}
MacCann et al. [Emotion, 14(2), 358-374 (2014)] explored various unidimensional, oblique, hierarchical and bifactor models to suggest that ability EI can represent a distinct set of cognitive abilities that can be placed within existing intelligence frameworks. The current study presents a conceptual replication of these analyses from data collected using alternative (non-proprietary) measures. Using a data set of 830 individuals, the current study provides further evidence to suggest ability EI best represents a hierarchical construct formed of emotion perception, understanding and management factors, structured as a second stratum factor within broader models of cognitive ability.
\end{abstract} Key words: Emotional intelligence; Mayer-Salovey-Caruso Emotional Intelligence Test (MSCEIT); Cattell-Horn-Carroll (CHC) theory; Structural Equation Modelling (SEM); Confirmatory Factor Analysis (CFA) 


\section{A Conceptual Replication of Emotional Intelligence as a Second-Stratum Factor of Intelligence}

Emotional intelligence (EI) is a label assigned to a wide array of affect-related individual differences, which, over the past 20 years, have been widely adopted by scholarly researchers and practitioners. Adopting a cognitive ability perspective, Mayer, Roberts and Barsade (2008) defined EI as "the ability to carry out accurate reasoning focused on emotions and the ability to use emotions and emotional knowledge to enhance thought" (p.511). This approach is commonly referred to as 'ability EI' to differentiate itself from other EI perspectives and has been refined to represent the cognitive abilities underpinning the perception, understanding, and management, of emotion (Fan et al., 2010).

The status of ability EI as a type of intelligence has been contested, however its theoretical context is important to a number of recent theoretical models such as the IMAID (Hughes \& Evans, 2018) which seek to integrate EI with existing individual difference frameworks. Definitional, correlational and developmental criteria have been devised and tested to determine whether ability EI can be considered an intelligence type, with broadly supportive results (e.g. Mayer, Caruso, \& Salovey, 1999). There is growing evidence to suggest that ability EI can represent a distinct set of cognitive abilities, not simply affective domains of existing abilities, that can be placed within existing intelligence frameworks (Bowman, Markham \& Roberts, 2002; Mayer, Salovey, Caruso, \& Sitarenios, 2001). For example, MacCann (2010) adopted non-proprietary measures to differentiate ability EI from fluid and crystallised intelligence, however there has been little testing of a priori theoretical models (MacCann et al. 2014).

The most robust investigation of the standing of ability EI within intelligence frameworks comes from MacCann et al. (2014) whom tested various unidimensional, oblique, hierarchical and bifactor models using questionnaire data collected from 688 students. Their data best fit the model in which ability EI, loaded by perception, understanding and management factors, was hierarchically structured under a general intelligence factor alongside broad ability domains such as quantitative reasoning, fluid intelligence, crystalized intelligence, and visual-spatial ability. It was summarised that ability EI could therefore be best understood as a second-stratum ability within the Cattell-Horn-Carroll (CHC) theory 
of intelligence (McGrew, 2009), with a similar standing to that of these other cognitive abilities (MacCann et al., 2014).

MacCann et al. (2014) used the Mayer-Salovey-Caruso Emotional Intelligence Test to capture ability EI (MSCEIT; Mayer, Salovey, Caruso, \& Sitarenios, 2003), which is one of the most well-known EI tools (Fiori et al., 2014). There are so few alternative measures of ability EI that the measure and model are often considered analogous (Fiori et al., 2014). Overreliance on this one measure is problematic however, as it is difficult to differentiate test effects from construct effects (MacCann \& Roberts, 2008). Furthermore, the MSCEIT has been critiqued for a number of reasons (Mayer, Salovey, Caruso, \& Sitarenios, 2003), including its proprietary status, factor structure, internal reliability, and validity of individual subscales (Fan et al., 2010; Palmer, Gignac, Manocha, \& Stough, 2005). Concerns have also been raised regarding the extent to which the MSCEIT can differentiate individuals with moderate or high levels of ability EI (Fiori et al., 2014), and the implications of a consensus-based scoring method that captures emotional conformity and measurement error (Legree et al., 2005; Maul, 2012).

Based upon the problematic status of the MSCEIT and the psychometric properties of the data it produces, the current study presents a conceptual replication of the MacCann et al. (2014) analyses from data collected using alternative non-proprietary measures. Using a data set of 830 individuals, the current study aims to determine whether previous findings represent MSCEIT test effects, or whether conclusions surrounding the second-stratum structure of ability EI within the CHC model can be considered robust.

\section{Method}

\section{Participants}

To meet the most conservative rule-of-thumb estimates (i.e. 10 participants per indicator), 620 participants were sought (Bentler \& Chou, 1987; Nunnally, 1967). Five-hundred and twenty-seven participants were convenience sampled through Qualtrics. A further 303 participants were recruited through a University research participation scheme and through convenience sampling of social 
network contacts. In total, 830 individuals (556 females) participated, with $44 \%$ aged between 18 and 30, 25\% aged between 31 and 45, 31\% aged between 46 and 70, and 4 participants that were 71 years old or older. There was no missing data.

\section{Procedure}

Ethical Approval was gained from Coventry University Health and Life Sciences Ethics Board. All participants, regardless of recruitment method, completed the study online, either through Bristol Online Survey or Qualtrics. Participants were provided a participation information sheet then completed the consent form and battery of questionnaires before being debriefed. Participation was part of a larger questionnaire which also featured measures of personality and emotion regulation, and typically took around 60 minutes to complete.

\section{Materials}

Fluid Intelligence - Fluid intelligence was measured by the ICAR 9-item Letter and Number Series task (Condon \& Revelle, 2014). Participants answer with one of eight answers. Cronbach's Alpha was calculated at .83 .

Crystallised Intelligence - Crystallised intelligence was assessed by the ICAR 16-item verbal reasoning task whereby participants picked one of eight answers. A Cronbach's Alpha of .81 was calculated.

Emotion Perception - Emotion perception was captured by the Ant-Colony Optimised Reading Mind in the Eyes Test (Baron-Cohen et al., 2001; Olderbak et al., 2015). Ten images of eyes were presented and participants chose from 4 options each to identify the emotion being experienced. Unlike the original measure, this optimised-version is appropriate because it has acceptable internal reliability, and moderately correlates with emotional perception as captured by The DANVA 2 Faces subscale (Nowicki \& Duke, 1994). The Cronbach’s Alpha was slightly less than desirable at .59.

Emotion Management - Emotion management was measured by the Situational Test of Emotion Management Short Form (Allen et al., 2015). The data had a Cronbach's Alpha of .65 and involved 
18 Situational Judgement Test items answered by one of four options, scored according to expert mean ratings (MacCann \& Roberts, 2008).

Emotion Understanding - Emotion understanding was assessed by the Situational Test of Emotion Understanding Brief, with a 19-item Situational Judgement Test format, five response options and a Cronbach's Alpha of .74.

\section{Results}

\section{Reliability, Descriptive Statistics, and Correlations between Variables}

Reliability and descriptive statistics for all measures are shown in Table 1. Cronbach's Alpha estimates were marginal for Emotion Perception and Emotion Understanding but were acceptable for all other measures. Pearson correlations among the cognitive ability and ability EI scores are shown in Table 1. This matrix demonstrates positive manifold: correlations between all scales are positive. Concurrent with MacCann et al. (2014), correlations among ability EI markers tend to be higher (average $r=.50$ ) than correlations between the ability EI and general cognitive ability markers (average $r=.38)$.

Table 1: Reliability, descriptive statistics and correlations for all measures

\begin{tabular}{lllllll}
\hline & $\begin{array}{l}\text { Mean } \\
\text { (SD) }\end{array}$ & $\mathbf{1}$ & $\mathbf{2}$ & $\mathbf{3}$ & $\mathbf{4}$ & $\mathbf{5}$ \\
\hline 1. Fluid & 4.43 & $(.83)$ & $.61^{*}$ & $.28^{*}$ & $.35^{*}$ & $.33^{*}$ \\
Intelligence & $(2.79)$ & & & & & \\
\hline 2. Crystallised & 9.26 & & $(.81)$ & $.39^{*}$ & $.45^{*}$ & $.50^{*}$ \\
Intelligence & $(3.65)$ & & & & & \\
\hline 3. Emotion & 7.31 & & $(.59)$ & $.43^{*}$ & $.48^{*}$ \\
Perception & $(2.04)$ & & & & \\
\hline 4. Emotion & 10.08 & & & & & \\
Understanding & $(2.70)$ & & & & $.650^{*}$ \\
\hline
\end{tabular}




\begin{tabular}{lll}
\hline 5. Emotion & 10.87 & (.74) \\
Management & $(3.14)$
\end{tabular}

Note: Cronbach's Alpha reported along the diagonal. $*=p<.01$

\section{Structural Models}

In accordance with the original analyses conducted by MacCann et al. (2014), eight a priori models were tested (See Figure 1). First, three models using just the ability EI data explored: a unidimensional model (Model 1); a hierarchical model where Perception, Understanding, and Management factors loaded onto a second-order ability EI factor (Model 2); and a bifactor model of ability EI where each indicator loaded onto both a general ability EI factor as well as their specific sub-factor (Model 3). Second, five models using all data explored: a unidimensional model where all ability EI and cognitive ability markers loaded onto a $g$ factor (Model 4); an oblique five-factor model where five factors of Perception, Understanding, Management, Gf and Gc correlate freely (Model 5); a hierarchical five-factor model where the five factors from Model 4 define an overall $g$ factor (Model 6); a hierarchical model with ability EI as a second-stratum ability, such that a second-order ability EI factor is defined by Perception, Understanding, and Management factors, and a higher-order $g$ factor is defined by Gf, Gc, and the ability EI factor (Model 7); and a bifactor model where each indicator defined both a $g$ factor and one of the five broad group factors described in Model 5 (Model 8; See MacCann et al., 2014).

All models were run using MPlus 6.0 and the Weighted Least Squares Means and Variances (WLSMV) estimator, which was considered most appropriate for the categorical and likert-type data collected as it makes no assumptions regarding distribution or levels of measurement (Browne, 1984; Muthén \& Muthén 2010). Consistent with MacCann et al. (2014) and the recommendations of general simulation data (e.g., Hu \& Bentler, 1999), we consider the CFI, TLI, and RMSEA when evaluating model fit. Because the SRMR is not produced with WLSMV estimation we were unable to report this statistic. Fit was considered adequate with values of $\leq .08$ for the RMSEA (Browne \& Cudeck, 1993) and $\geq .90$ for the CFI and TLI (Bentler \& Bonnett, 1980) with values above .95 preferred (Hu \& Bentler, 1999). Chi Square is extremely sensitive to sample size and so whilst presented, is not used 
for evaluation of model fit. Similarly, WRMR is an experimental fit statistic, and thus whilst included for completeness, is not used to evaluate model fit (Muthén \& Muthén 2010). See Supplementary Materials for all model matrices. 


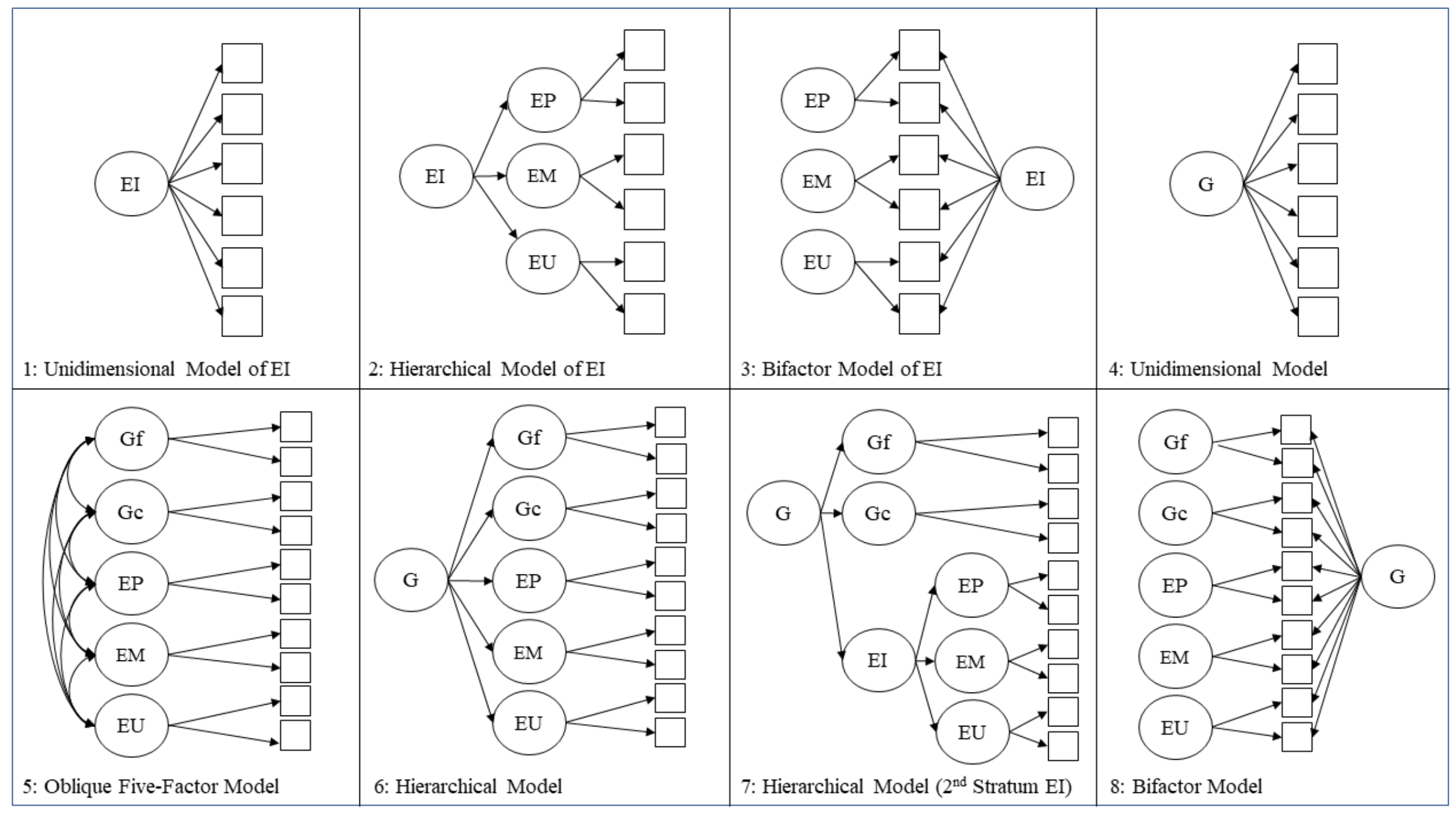

Figure 1: Simplified illustrations of the eight models tested; $\mathrm{G}=$ intelligence; $\mathrm{Gf}=$ fluid intelligence; $\mathrm{Gc}=$ crystallised intelligence; $\mathrm{EP}=$ Emotion Perception; $\mathrm{EU}=$ Emotion Understanding; $\mathrm{EM}=$ Emotion Management 
Model 1: A unidimensional model of the ability EI test items did not show good fit $\left(X^{2}(1034, N=\right.$ $830)=1273.29, p<.001 ; \mathrm{RMSEA}=.017 ; \mathrm{CFI}=.891 ; \mathrm{TLI}=.886 ; \mathrm{WRMR}=.900)$. The average item loading was .36 , ranging -.24 to .80 .

Model 2: After fixing the factor variance of Emotion Understanding to zero to resolve a Heywood Case, the hierarchical model of ability EI shows good fit $\left(X^{2}(1032, N=830)=1205.55, p<.001\right.$; $\mathrm{RMSEA}=.014 ; \mathrm{CFI}=.921 ; \mathrm{TLI}=.917 ; \mathrm{WRMR}=.855)$. The average item loading on each factor: Emotion Perception (.47: range .33 to .59 ); Emotion Understanding (.39: range -.25 to .81); Emotion Management (.35: range .18 to .61$)$; second-order ability EI (.88: range .80 to 1.0$)$.

Model 3: Various bifactor models, where each of the items loaded once onto its theorised group factor and once onto a general ability EI factor, were tested. Possibly due to the use of item-level analysis, rather than scale-scores as conducted by MacCann et al. (2014), no model converged. Constraining factor variance and relationships between group scores was unsuccessful, as was increasing the number of iterations. As such, a bifactor model was not compatible with the current data.

Model 4: A unidimensional model of the cognitive tests and the ability EI tests together did not show $\operatorname{good}$ fit $\left(X^{2}(2484, N=830)=4142.75, p<.001 ;\right.$ RMSEA $=.028 ;$ CFI $=.813 ;$ TLI $=.808 ;$ WRMR $=$ 1.292). The average item loading was .41 , ranging -.21 to .76 .

Model 5: A five-factor oblique model with two cognitive ability sub-factors and three ability EI subfactors fitted the data well $\left(X^{2}(2474, N=830)=3017.29, p<.001 ;\right.$ RMSEA $=.016 ; \mathrm{CFI}=.939 ;$ TLI $=.937 ; \mathrm{WRMR}=.969)$. The average item loading on each factor: Gf (.75: range .65 to .86$)$; Gc (.61: range .33 to .81 ); Emotion Perception (.46: range .29 to .57 ); Emotion Understanding (.39: range -.24 to .82); Emotion Management (.34; range .18 to .56). The mean latent factor correlation was .63 $($ range $=.43$ to .84$)$.

Model 6: Next, the factor intercorrelations from Model 5 were replaced by a single, higher-order $g$ factor. The loadings of the five lower factors onto the higher-order $g$ were all strong (ranging from .72 to .90 ; average=.79). Model fit was good, however slightly worse than the oblique five-factor model $\left(X^{2}(2479, N=830)=3339.76, p<.001 ; \mathrm{RMSEA}=.020 ; \mathrm{CFI}=.903 ; \mathrm{TLI}=.900 ; \mathrm{WRMR}=1.068\right)$. 
The average item loading on each factor were: Gf (.75: range .64 to .87); Gc (.61: range .33 to .81); Emotion Perception (.46: range .29 to .57$)$; Emotion Understanding (.39: range -.25 to .82); Emotion Management (.34; range .18 to .54$)$.

Model 7: Ability EI (loaded by three sub-facets: Perception, Understanding and Management) was modelled as a second-stratum factor of $g$, alongside fluid and crystallised intelligence. After fixing the factor variance of Gc to zero to resolve a Heywood Case, the model produced good fit to the data $\left(X^{2}\right.$ $(2479, N=830)=3016.59, p<.001 ; \mathrm{RMSEA}=.016 ; \mathrm{CFI}=.939 ; \mathrm{TLI}=.938 ; \mathrm{WRMR}=.971)$. The average item loadings were: Gf (.75: range .65 to .86$)$; Gc (.62: range .33 to .82$)$; Emotion Perception (.46: range .29 to .57$)$; Emotion Understanding (.39: range -.24 to .82); Emotion Management (.34; range .18 to .56$)$. Loadings onto the ability EI factor were strong (.88; ranging .82 to .98$)$, and the loading of ability EI onto the $g$ factor (.70) was of similar magnitude to the g-loadings of fluid intelligence (.74).

Model 8: Various bifactor models, where each of the items loaded once onto the group factor and once onto $g$, were tested. Possibly due to the use of item-level analysis, rather than scale-scores as conducted by MacCann et al. (2014), no model converged. Constraining factor variance and relationships between group scores was unsuccessful, as was increasing the number of iterations. As such, a bifactor model was not compatible with the current data. Given there is covariance between cognitive abilities, and there are no bifactor theories of intelligence, the assumptions of the bifactor model may be less theoretically appropriate than the alternative models captured (Murray \& Johnson, 2013). The lack of a fitting bifactor model was therefore not considered problematic.

In sum, model fit indices suggest the oblique five-factor model and the hierarchical model with ability EI at the second stratum (models 5 and 7 respectively) represent similarly plausible models of the current data. Given substantive debate surrounding the importance of the g factor (McGrew, 2009), both models can be considered concurrent in presenting ability EI at the second-stratum of cognitive ability, and relevant for inclusion in the $\mathrm{CHC}$ model. 


\section{Discussion}

The current study provided a conceptual replication of analyses conducted by MacCann et al. (2014) to examine whether ability EI fits within factor models of broad cognitive ability. Concurrent with the original results and the broad body of evidence highlighting the value of hierarchical models for structuring cognitive abilities, the current paper argues that ability EI can be considered a secondstratum factor of the $\mathrm{CHC}$ model. As to whether an oblique or hierarchical model presents the best current available model of understanding, theory should be considered alongside fit indices (Murray \& Johnson, 2013). In this regard, the hierarchically structured model which is consistent with the CHC model of intelligence would seem preferable, especially because such a model would require only limited changes as predicted by $\mathrm{CHC}$ theory (i.e., the addition of another second-stratum factor; McGrew, 2009). Thus, considering both model fit and well-established theory, the results of the current study are consistent with MacCann et al. (2014) in suggesting that ability EI is best considered as a hierarchically structured (loaded emotion perception, understanding and management) secondstratum factor within the CHC model of intelligence (MacCann et al., 2014).

Beyond replicating the results of MacCann et al. (2014), the current findings provide a unique contribution to our understanding. The current study had a large sample of participants and used different measures for all intelligence and ability EI facets captured. Given the intimate links between the MSCEIT (used by MacCann et al. 2014) and the development of ability EI theory, the replication of these findings using alternative measures provides evidence to indicate that such results are unlikely to represent test effects. Together, the findings provide convincing support for situating ability EI within the CHC model as a second stratum factor of intelligence, separate to fluid or crystallised intelligence.

The measurement and structure of ability EI has been dominated by the MSCEIT (Mayer et al. 2003, formerly MEIS). Thus, the current study adopted alternative non-proprietary measures: an optimised version of the Reading Mind in the Eyes Test (Baron-Cohen et al. 2001; Olderbak et al. 2015), and brief versions of the Situational Test of Emotion Management and Situational Test of Emotion Understanding (Allen et al. 2014; 2015). Findings from the data presented suggest that these other 
measures provide a viable theoretically appropriate alternative to the proprietary MSCEIT. Due to the financial costs associated with the MSCEIT, there have been a number of calls for alternative free and open-access measures (Mestre et al. 2016). The measures adopted for the current study address these calls and may offer wider opportunities for research projects to adopt ability EI.

The current study adopted few, and brief, measures to minimise participant fatigue. As a result, there is limited content coverage of intelligence as a whole, and relatively narrow representation of fluid and crystallised intelligence, although scores on the scales adopted closely approximate scores derived from longer measures (Condon \& Revelle, 2014). Further replications of the current findings with greater content coverage (using multiple tests of several abilities) are vital to minimise distortion of estimates due to method-related variance and increase the likelihood that bifactor models can be estimated. In addition, future research that develops additional non-proprietary ability EI measures that exhibit excellent psychometric properties would allow for more reliable estimates of constructlevel variance. This is a particularly pertinent priority given the psychometric shortcomings of the MSCEIT and the low reliability of the emotion perception and emotion understanding sub-factors of the scales used here (see also Austin, 2010; Olderbak et al., 2015).

In sum, the current study adds to the growing body of evidence that situates ability EI within frameworks of cognitive ability, replicating the main conclusions of MacCann et al. (2014). Currently, ability EI best represents a hierarchical construct formed of emotion perception, understanding and management factors, structured as a second stratum factor within the $\mathrm{CHC}$ model. 


\section{References}

Allen, V. D., Rahman, N., Weissman, A., MacCann, C., \& Roberts, R. D. (2015). Development and validation of the Situational Test of Emotional Management-Brief (STEM-B) using item response theory and latent class analysis. Personality and Individual Differences, 81, 195200.

Allen, V. D., Weissman, A., Hellwig, S., MacCann, C., \& Roberts, R. D. (2014). Development of the situational test of emotional understanding - Brief (STEUB) using item response theory. Personality and Individual Differences, 65, 3-7.

Austin, E. J. (2010). Measurement of ability emotional intelligence: Results for two new tests. British Journal of Psychology, 101(3), 563-578.

Baron-Cohen, S., Wheelwright, S., Hill, J., Raste, Y., \& Plumb, I. (2001). The "Reading the Mind in the Eyes" Test revised version: a study with normal adults, and adults with Asperger syndrome or high-functioning autism. The Journal of Child Psychology and Psychiatry and Allied Disciplines, 42(2), 241-251.

Bentler, P. M., \& Bonett, D. G. (1980). Significance tests and goodness of fit in the analysis of covariance structures. Psychological Bulletin, 88(3), 588-606.

Bentler, P. M., \& Chou, C. P. (1987). Practical issues in structural modeling. Sociological Methods \& Research, 16(1), 78-117.

Bowman, D. B., Markham, P. M., \& Roberts, R. D. (2001). Expanding the frontier of human cognitive abilities: so much more than (plain) g! Learning and Individual Differences, 13, $127-158$.

Browne, M. W. (1984). Asymptotically distribution-free methods for the analysis of covariance structures. British Journal of Mathematical and Statistical Psychology, 37(1), 62-83. 
Browne, M.W. \& Cudeck, R. (1993). Alternative ways of assessing model fit. In Bollen, K.A. \& Long, J.S. (Eds.), Testing Structural Equation Models (pp.136-162). Newbury Park, CA: Sage.

Condon, D. M., \& Revelle, W. (2014). The International Cognitive Ability Resource: Development and initial validation of a public-domain measure. Intelligence, 43, 52-64.

Fan, H., Jackson, T., Yang, X., Tang, W., \& Zhang, J. (2010). The factor structure of the MayerSalovey-Caruso Emotional Intelligence Test V 2.0 (MSCEIT): A meta-analytic structural equation modeling approach. Personality and Individual Differences, 48(7), 781-785.

Fiori, M., Antonietti, J. P., Mikolajczak, M., Luminet, O., Hansenne, M., \& Rossier, J. (2014). What is the ability emotional intelligence test (MSCEIT) good for? An evaluation using item response theory. PloS one, 9(6), e98827.

Hu, L. T., \& Bentler, P. M. (1999). Cutoff criteria for fit indexes in covariance structure analysis: Conventional criteria versus new alternatives. Structural Equation Modeling: A Multidisciplinary Journal, 6(1), 1-55.

Hughes, D. J., \& Evans, T. R. (2018). Putting ‘Emotional Intelligences' in Their Place: Introducing the Integrated Model of Affect-Related Individual Differences. Frontiers in Psychology, 9. Doi:10.3389/fpsyg.2018.02155

Legree, P. J., Psotka, J., Tremble, T., \& Bourne, D. R. (2005). Using Consensus Based Measurement to Assess Emotional Intelligence. In R. Schulze \& R. D. Roberts (Eds.), Emotional Intelligence: An International Handbook (pp. 155-179). Ashland, OH: Hogrefe \& Huber.

MacCann, C. (2010). Further examination of emotional intelligence as a standard intelligence: A latent variable analysis of fluid intelligence, crystallized intelligence, and emotional intelligence. Personality and Individual Differences, 49(5), 490-496.

MacCann, C., \& Roberts, R. D. (2008). New paradigms for assessing emotional intelligence: theory and data. Emotion, 8(4), 540-551. 
MacCann, C., Joseph, D. L., Newman, D. A., \& Roberts, R. D. (2014). Emotional intelligence is a second-stratum factor of intelligence: Evidence from hierarchical and bifactor models. Emotion, 14(2), 358-374.

Maul, A. (2012). The validity of the Mayer-Salovey-Caruso Emotional Intelligence Test (MSCEIT) as a measure of emotional intelligence. Emotion Review, 4(4), 394-402.

Mayer, J. D., Caruso, D. R., \& Salovey, P. (1999). Emotional intelligence meets traditional standards for an intelligence. Intelligence, 27(4), 267-298.

Mayer, J. D., Roberts, R. D., \& Barsade, S. G. (2008). Human abilities: Emotional intelligence. Annual Reviews of Psychology, 59, 507-536.

Mayer, J. D., Salovey, P., Caruso, D. R., \& Sitarenios, G. (2001). Emotional intelligence as a standard intelligence. Emotion, 1(3), 232-242.

Mayer, J. D., Salovey, P., Caruso, D. R., \& Sitarenios, G. (2003). Measuring emotional intelligence with the MSCEIT V2.0. Emotion, 3(1), 97-105.

McGrew, K. S. (2009). CHC theory and the human cognitive abilities project: Standing on the shoulders of the giants of psychometric intelligence research. Intelligence, 37(1), 1-10.

Mestre, J. M., MacCann, C., Guil, R., Roberts, R. D. (2016). Models of cognitive ability and emotion can better inform contemporary emotional intelligence frameworks. Emotion Review, 8 (4), $322-330$.

Murray, A. L., \& Johnson, W. (2013). The limitations of model fit in comparing the bi-factor versus higher-order models of human cognitive ability structure. Intelligence, 41(5), 407-422.

Muthén, L.K. \& Muthén, B.O. (2010). Mplus User's Guide. Sixth Edition. LA, CA: Muthén \& Muthén 
Nowicki, S., \& Duke, M. P. (1994). Individual differences in the nonverbal communication of affect: The Diagnostic Analysis of Nonverbal Accuracy Scale. Journal of Nonverbal Behavior, 18(1), 9-35.

Nunnally, J.C. (1967). Psychometric theory. New York: McGraw-Hill.

Olderbak, S., Wilhelm, O., Olaru, G., Geiger, M., Brenneman, M. W., \& Roberts, R. D. (2015). A psychometric analysis of the reading the mind in the eyes test: toward a brief form for research and applied settings. Frontiers in Psychology, 6, 1503.

Palmer, B. R., Gignac, G., Manocha, R., \& Stough, C. (2005). A psychometric evaluation of the Mayer-Salovey-Caruso Emotional intelligence test version 2.0. Intelligence, 33(3), 285-305. 